\title{
Sister to Sister: Becoming Literate in Relation
}

\author{
AMY BARNHILL \\ The University of Houston-Victoria \\ DON HALQUIST \\ The College at Brockport, State University of New York
}

\section{Introduction}

My sixteen years as a teacher of literacy have helped me (Amy) become innately aware of and sensitive to how children emerge in their literacy development. These instinctive abilities are part of who I am and what I do. For the past three years, I have been observing how the various interactions and relationships between and among my own four children encourage, support and promote literacy development, and I have found myself looking not only at each child individually but also how all four siblings impact and support each other's literacy learning.

My curiosity with and exploration of my own children's literacy development is not unique; in fact, the model of parent as researcher is a well-established tradition in the field of literacy research (e.g., Baghban, 1984; Bissex, 1980; Cook, 2005; Doake, 1988; Schwarzer, 2001). According to Glenda Bissex (1980), who detailed her son's emerging literacy development, "The parent/researcher comes to the research with an 'enlightened subjectivity" (p. vi). For me, my parent/researcher vantage point offers sustained engagement with my children's daily challenges, accomplishments and growth, and provides clues and insights into how their interactions and relationships as siblings support their literacy development.

In this article, a former colleague (Don) and I draw on a portion of data from a larger, longitudinal study of the literacy interactions among my four children to provide insight into the relational practices created when my two oldest children-Anna, age 6.5, and Mirela, age 4.0 engaged in literacy experiences together. In particular, we focus on how, through three literacy events, the girls' interactions expand and enhance each child's literacy development.

\section{Parents, Siblings and Literacy}

For decades, researchers have studied family literacy and the role parents, caregivers, and the home environment play in the literacy development of young children (Cicirelli, 1972; Handel, 1999; Morrow, Paratore, \& Tracy, 1994; Taylor, 1983). The impact of how parent-child interactions build literacy practices within the home and the role the family can have on school achievement has also been explored and validated (e.g., Berger, 2000; Epstein, 1995, Swick, 1991). Recently there has been a shift away from seeing the adult as expert toward viewing the child as a conspirator or co-constructer of meaning with the adult, a shift that has produced research centered on the knowledge the child brings to the situation and how that knowledge changes based on interactions with others, either adults or children (Gregory, 2001).

There is a teaching-learning process that occurs when siblings interact (Brody, Stoneman, \& MacKinnon, 1982; Ervin-Tripp, 1989). Often, these interactions build, promote and sustain literacy learning (Goldfarb, 2000; Gregory, 2001; Volk, 1999). The older sibling acts as the teacher and the younger sibling as the learner. Until recently, this relationship, or interaction, was considered unidirectional: the older, more experienced child teaching the younger child. However, as Gregory (2001) points out, it is not simply a transmission of knowledge from the 
older sibling to the younger sibling; rather both parties are learning in the interaction. The younger sibling not only learns the new information but acts as a trigger enabling the older sibling to move to a deeper level of understanding, internalizing the information more fully while practicing adult-like roles. Gregory (2001) describes the siblings' mutually beneficial learning process as "synergy." It is this mutuality and the various ways in which Anna and Mirela stimulate and foster each other's literacy development that is the focus of our work.

\section{Participants and Settings}

\section{Methods}

Anna is the oldest of my four children. At the time of this portion of the study Anna was between 6.0 and 6.5 years of age and attending full day kindergarten five days a week. In the United States, children attend kindergarten, a child's first year of compulsory education, between the ages 5 or 6 . Anna was 5.7 years old when she began her kindergarten experience.

Anna shared her classroom with 20 peers, one teacher and one teacher's aide. Her teacher used a balance literacy approach to literacy instruction: read aloud, guided reading, and a range of interactive reading and writing activities including the traditional morning message, in which the students chose the topic. The classroom library included a wide range of reading materials and supported the children's ability to choose books and read independently. The teacher was a strong supporter of authentic and meaningful literacy activities, even giving the students a book for their birthdays.

Anna's literacy development was, according to her teacher's reports, at or above the level of a typically developing kindergartener; she enjoyed reading and writing both at school and at home. As a typical first born child, Anna often led her siblings in various play activities.

Mirela is my second child and was between 3.5 and 4.0 years of age at the time of this study. She was attending an accredited early childhood care center three days per week for three hours each day. According to the developmental report produced by her teachers, Mirela's reading and writing knowledge appeared to be on target for her age. At home, Mirela often engaged in play with all three of her siblings. When she played with Anna she followed Anna's suggestions and often used questions to clarify various aspects of their play.

The girls live with their younger brother and sister, and my husband and me in the southwest United States. My husband and I are college educated; I have a Ph.D. in education. The environment in our white, middle-class household promotes and supports the acquisition and use of multiple literacies. The physical props required for reading and writing are readily accessible to the children. Crayons, pencils, pens, markers, paper and other art supplies are kept in a hall closet, which the children can access any time they are inspired to write or draw. In the girls' bedroom there is a large bookshelf packed full of children's books.

In addition to the physical presence of reading and writing materials, my husband and I demonstrate reading, writing, listening, viewing and speaking daily. My husband, a stay-athome dad, is adamant about reading the daily newspaper and searching the Internet for more news and information. He writes for real purposes - documenting schedules, composing grocery lists, and jotting notes to himself, me or the kids. Much of the reading I do is related to my work as a literacy educator and is done at my college office. However, at home, I read mail, newspapers, magazines, and most often, student work, which I bring home to grade. Within our home, my husband and I send the message that reading, writing, listening and speaking, even viewing, are basic functions of living. Cambourne (1995) would say that our family is engaged in literacy. The elements necessary for engagement are present. The children 
believe that they can do what their parents do. They see purpose and value in all forms of literacy, they are free from anxiety, and they like and respect the people who are demonstrating the multiple forms of literacy.

\section{Data Collection and Analysis}

The three literacy events - name writing, weather calendar, and read aloud - took place over a three-week period and were instigated by Anna with Mirela as a willing participant. I collected the literacy artifacts - posters, cards and other written materials - that the girls created during their interactions and reviewed them during the analysis process. I audio taped the girls' interactions and then transcribed the tapes in order to analyze the girls' conversations more effectively. I also documented the literacy events and my own insights into the girls' developing literacy relationships in a research journal.

We read and reread the artifacts and transcripts multiple times chunking the data according to topic. We then reviewed the individual chunks, coding the data and noting patterns, a process that led to the creation of the four themes - the role of questions, playing with literacy, sister as conduit and mutually beneficial interactions.

\section{Literacy Events}

The three events represent typical interactions between Anna and Mirela. They are typical in the sense that they bubbled up naturally within contexts of the girls' day-to-day interactions and are representative of scenarios in the girls' play repertoire.

\section{Name Writing}

This exchange took place as Anna and Mirela were putting the final touches on a very large (18 x 24) poster prior to showing it to my husband and me. Mirela, in an effort to label her portion of the poster, attempted to write her name (see figure 1).

Mirela: $\quad$ Why do you want to write? Is that mine? (seated next to Anna and watching Anna write her name on the poster)

Anna: $\quad$ Yep. Mirela Barnhill. Now I'm going to...

Mirela: Why do I, why do I have an "n" in my name? (looking at her last name)

Anna: It's not an " $n$ ". What do you mean? (looking at the " $m$ " in Mirela's first name)

Mirela: $\quad$ That. (pointing to the " $n$ " in Barnhill)

Anna: $\quad$ Oh, this is not your name. It's your LAST name.

At the age of 3.5, Mirela recognized most of the letters in her first name. However, she did not yet recognize all of the letters in her last name. Understandably, through her life and school experiences, Anna, at the age of 6.0, had acquired more literacy abilities than Mirela. She knew how to write Mirela's first and last name and she knew the difference between an " $m$ " and an "n". Her awareness of the alphabetic principle was clearly developed while Mirela was still emerging in her understanding of letter and sound relationships.

As Cambourne (1995) posits, the learner has a responsibility, or decision to make, about what she will learn. Mirela's confusion about Anna's actions led her to attend to the letter "n" and provided Anna, the more knowledgeable other, with an opportunity to highlight the concept of first and last names. Mirela's attention to the letter " $n$ " triggers or enables Anna to scaffold her 
in her understanding of last names while at the same time clarifying and reinforcing Anna's own understanding of the concept.

Anna's response, "Oh, this is not your name, It's your LAST name" to Mirela's query about the letter " $n$ " is particularly interesting. Anna's emphasis on "LAST" signifies her recognition of the concept of first and last names, a distinction she only partially reveals to Mirela. She doesn't, for example, say "Mirela is your FIRST name," nor does she elaborate upon the concept of a last name by offering an explanation such as "Your last name is Barnhill."

\section{Weather Calendar}

In this next event, Anna and Mirela were playing calendar, a common activity in early childhood classrooms where the children sit near an oversized calendar as the teacher prompts discussions about the days of the week, numbers, dates, patterns and counting, and weather. In the girls' rendition, Anna, as the teacher, stood next to a calendar while Mirela, her student, was seated on the floor.
Anna:
O.K. All right. What does it look like outside? I want Mirela to do this. What does it look like outside? What's it look like outside?
Mirela:
Dark.
Anna: Sunny or snowy, overcast or rainy?
Mirela:
Dark.
Anna:
No, that's not the weather.
Mirela:
Snowy?
Anna:
Yes! You got it. That's right! It is snowing.

Anna initiated the calendar activity with typical, teacher-like diction, first asking a question, then focusing her student's attention through the use of her name, followed by a replication of the original question, and then one that is slightly altered. She responds to Mirela's answer of "dark" by rephrasing the original question, even offering a selection of possibilities. When Mirela repeated her original response, "dark," Anna was more direct in her response and introduced the concept of weather. Mirela's tentative "snowy" was met with a positive and enthusiastic affirmation from Anna.

Mirela's literal interpretation and observation that it was "dark" outside was accurate; however, in this exchange that description was not an acceptable weather term and was rejected by Anna. Given her limited school experience, Mirela had not yet learned the calendar protocol or the acceptable weather choices. Anna, in an effort to continue the scenario and the exchange, supports Mirela's process and efforts through her choice of language cues, first inviting her to "look outside" and then by offering a selection of weather choices. Anna's language choices closely parallel the language a teacher might use during a calendar activity and highlights how teachers often employ the use of closed questions during such activities. There is only one acceptable answer and it is up to the student to determine the correct choice. Mirela's limited understanding of the calendar protocol and acceptable weather terminology created an opportunity for Anna to refine her questioning strategies while building on Mirela's weather schema. 


\section{Read Aloud}

In this event, the girls were engaged in another common school activity: read aloud. Anna, the teacher, was sitting in a child-sized chair while Mirela, her student, sat on the floor. Anna held the book Peter's Chair by Ezra Jack Keats (1998), a story of a young boy who gives his childhood chair to his new baby sister. Anna did not yet know how to read the book's text, so she created her own version of the story for Mirela. Anna's "reading" of the text appears in italics.

Anna: $\quad$ The story I'm going to read you today is Peter and His Little Sister. What do you think the story is about? Can anybody take a guess?

Mirela: $\quad$ Um, I don't know.

Anna: $\quad$ You don't know? Then don't raise your hand. It's ok. Does anybody want to take a guess? Look at it and see. What does that chair take the place of?

Mirela: $\quad$ A... little....

Anna: $\quad$ Yeah, it's little. So, do you think he might fit in it anymore? So, he might give it to his baby sister, let's see. Mirela had a really good idea - it's little. I think it was too little for him because he's a big guy. See, yeah, he's a big guy. He probably doesn't fit in that chair anymore. Let's see what the story begins with. See here's Peter. He's building a castle.

Peter said to hisself, Won't you be a real good friend to him?

Does Peter look sad?

Mirela: $\quad$ Yeah.

Anna: See they're painting it [the chair] pink. OK. See, do you like this picture, Mirela? They painted her bedroom pink with flowers on it.

Mirela: I like pink!

Anna: Oh, yeah you do. That's why I picked this book for ya. His father was painting a high chair for his little sister. Your mom and dad probably did it too. Whoever has a big sister raise their hand. (Mirela raises her hand.)

Mirela: $\quad$ It's two.

Anna: $\quad$ You've got two big sisters? One little sister and I think you've got a little brother too. So, Peter found the wood chair. What do you think he's going to do? Cause he is big. Mirela used the picture to see what Peter says. She probably looked at that baby. They probably have a baby in that story. So... old blue chair. He got it!! He ran and ran. And he said, See he ran, didn't he? Oops, I went backwards. So I guess this will be for my little sister, said Peter. He was trying to sit in it but it was too small. Good job, Mirela! You looked at the picture where it took place. Now, I see where we are in the story.

Mirela: $\quad$ Not that one. Not that one.

Anna: $\quad$ O.K. Peter thought for a minute...I think that chair is way too small for me. We're gonna make our own Peter story.

The read aloud, like the calendar event, was instigated by Anna and enabled her to repeat her role as teacher, and to tryout teacher-like language and procedures she has witnessed in her brief tenure as a student. Even as Anna rendered her own version of the story, complete with a new 
title, her intonation and inflection throughout much of the reading reflected clarity and fluidity, characteristics of a confident, experienced reader. She framed the read aloud in typical teacher fashion, asking her students to predict what the story might be about based on the book's title and cover illustration. Anna's admonishment of Mirela for raising her hand without knowing the answer reveals her understanding of classroom protocol, i.e., only students who know the answer should raise their hands. Perhaps Mirela was simply trying to be a good sport, to play along? She is after all the only student physically present. Anna's comments do not appear to deter Mirela as she quickly offers a response to Anna's next question about the chair. As in the calendar event, Anna rephrases her questions to sustain the conversation and support Mirela's ability to make sense of the story.

Anna also integrated and adapted Mirela' responses to continue and enhance the scenario, a strategy she used during the calendar event. For example, when Anna asked Mirela "What does that chair take the place of?" Mirela responded, "A... little". While not a complete or reasonable answer, Anna accepted it, began to analyze the story accordingly, and arrived at the notion that the chair was too little for Peter and that he probably needed a new one, an appropriate inference based on the story's pictures.

In her role as teacher, Anna supported Mirela's ability to relate to the context of the story by offering several possible connections, for example, "Whoever has a big sister raise their hand" and "Oh, yeah you do. That's why I picked this book for ya." She also highlighted and enthusiastically confirmed Mirela's use of picture clues, saying "Good job, Mirela! You looked at the picture where it took place."

Further, the read aloud reveals how Anna has internalized the reading strategies of predicting, clarifying, self-monitoring and inferencing. The read aloud, then, provided Anna with an opportunity to authentically practice the reading strategies, demonstrate them for Mirela, and move to a deeper understanding of how the strategies support her own ability to make meaning of the story.

\section{Discussion}

When we look across the three events, four themes, which supported, enabled, and enhanced both sisters' literacy abilities and development are revealed: playing with literacy, the role of questions, sister as conduit and mutually beneficial interactions.

\section{Playing with Literacy}

The three events enabled the girls to use language and literacy props easily and authentically. The calendar and read aloud events indicated that Anna was eager to share her literacy abilities with Mirela, and to educate her on the ways of school as she perceived them. Playing "school" was a common occurrence for the girls and provided Anna with a fun, nonthreatening environment to try on teacher-like behaviors-language and postures, and procedures.

The play events created environments in which Anna could easily and authentically share several literacy strategies with Mirela. For example, teachers often use the connections strategies - text-to-self, text-to-text and text-to-world - as a way to encourage students to comprehend what they are reading. Anna validated this strategy during the read aloud when Mirela stated, "I like pink" in response to seeing the pink bedroom. Anna acknowledged Mirela's response and followed up by asking another text-to-self connection question, "Whoever has a big sister raise their hand." 
Mirela, an enthusiastic playmate, eagerly accepted the invitation to engage in school play scenarios with Anna as they enabled her to build her literacy knowledge and learn more about how school works. There was give-and-take in each play event that allowed the scenario to unfold naturally and accommodate the girls' conversations. Playing with literacy in these ways created authentic contexts in which Anna and Mirela expand their cognitive and social abilities as well as their use oral and written language to communicate and support their ideas.

\section{The Role of Questions}

During the calendar and read loud events, Anna used questions authentically and effectively to provide an anticipatory set for the event and to motivate Mirela. In the calendar event, she asked "What does it look like outside?" to focus Mirela's attention on the weather. Before the read aloud, she asked "What do you think the story is about?" to provide motivation, build excitement and set a purpose for the event. In the name event, Anna asked Mirela "What do you mean?" in order to understand Mirela's confusion. Once she understood Mirela's confusion, Anna was able to provide Mirela with an explanation. "Oh, this is not your name. It's your LAST name."

Anna's classroom experiences have influenced her questioning techniques as well as her use of what to do with a playmate's, i.e., student's response. Teachers of young children often provide a scaffold to support or build upon their students' responses. One way Anna attempted to scaffold Mirela was to model her own thinking during the read aloud. When Mirela did not understand Anna's first prediction question about the chair, she went on to provide her own interpretation of the cover of the book. This enabled Mirela to witness Anna modeling the reading strategy of prediction.

Mirela's use of questions served a dual purpose: they served as a means through which she could build her knowledge in conversation with Anna and they acted as a prompt or trigger to enable Anna to explain concepts of weather terms or last names to Mirela.

\section{Sister as Conduit}

Anna may have used play as a way to make meaning of her own school experiences. In so doing, she furthered her own understanding of her experiences while exposing her sister to the rituals, and routines of early childhood classrooms and to the expectations of early childhood teachers. Viewed in this way, Anna serves as a conduit for Mirela's learning about schooled literacy and literacy knowledge.

Schooled literacy refers to the type of literacy interactions and literacy rules that are typified by schools (Cook-Gumperz, 1986; Powell, 1999). According to Powell and Davidson (2005), this model of literacy views reading and writing as a compilation of skills that can be taught and learned 'for school.' At times, the schooled literacy and knowledge was directly conveyed through conversation as in the name writing and weather calendar events. At other times, the learning was indirect, when, for example, Anna modeled the conventional spelling of Mirela's first and last names or when she modeled comprehension strategies such as prediction. Regardless of the method, the knowledge was transmitted via Anna, the older, more experienced child, who had already been exposed to and indoctrinated into some of the literacy requirements and expectations of school. 
When looking across three events, reveals some of Anna's understanding of schooled literacy and which in turn became part of the sisters' shared literacy repertoire. The protocol of raising a hand to answer a teacher's question, for example. To Anna, students raise their hand when they know the answer. Anna also recognizes that the teacher is often the person who gets to ask the questions and that often there is only one right answer to those questions.

The schooled literacy and knowledge that Anna brings into our home is, most likely, not an exact replica of what she experienced in her classroom for as Williams (2004) reminds us, children are simultaneously imitating, extending and exaggerating school practices through play. As a child attempts to make sense of what she is seeing and hearing in the classroom, she is shaping and transforming her reality through her play. In the calendar and read aloud events, Anna 'transforms or translates officially recognized 'meanings' to individual shared 'sense' and vice versa" (Gregory, 2001, p. 311); the end result is that Anna and Mirela have a shared sense of schooled literacy and literacy knowledge.

\section{Mutually Beneficial Interactions}

At first glance, one might assume that Mirela, simply by her positioning as the younger child, or less knowledgeable peer, is the learner. For Anna, though, her sister's responses triggered her ability to respond in ways that supported her sister. These moments enable Anna to expand her thinking and articulate and share her insights and understandings with Mirela. Mirela's questions instigated many of these moments, but Anna's desire to scaffold her "instruction" so that Mirela could continue to participate also stimulated Anna's thinking. The shared and heightened sense of schooled literacy and knowledge that resulted from these play events fuels future interactions between the sisters.

Anna and Mirela were equally invested in the play experiences and in the act of literacy inherent in each experience, a commitment that enabled and supported both sisters' abilities to be flexible and spontaneous. It is a shared process that is mutually beneficial to both girls' continued literacy development.

\section{Conclusion}

Researchers have, over the years, come to recognize the wealth of literacy related learning that occurs in the home (Mull, 1994), and understand and value the positive and influential roles that parents and other family members - siblings, grandparents, extended relatives - play in a child's literacy development (Barton, 1997). While my husband and I are integral to all four of our children's literacy growth, the three literacy events described above reveal the subtle and overt relational influences our daughters have had on one another and the rich potential such interactions hold for their continued literacy development.

Anna, as the oldest, attended school and brought much of her school knowledge of literacy into our home, eagerly sharing it with Mirela. Even though she did not consciously set out to "teach" Mirela during their play activities, Anna was, in fact, doing just that by providing explanations, elaborations and extensions, all the while skillfully working within Mirela's zone of proximal development (Vygotsky, 1989). Although this is an unconscious act on Anna's part, it is significant as it enables her to come to a more nuanced understanding of school, the values that are enacted and the behaviors that are expected there. Through her interactions with Mirela, Anna is transforming her own understandings of and abilities with reading, writing, listening, viewing and speaking. 
Mirela, for her part, is an enthusiastic and engaged protégé, ready to take on any literacy challenge that Anna presents. Couched in play, these challenges are authentic, fun and edifying. Through her apprenticeship (Lave, 1988; Rogoff, 1990) with Anna, Mirela is unconsciously acquiring oral and written language skills, and coming to a deeper awareness of conventional reading and writing through Anna's implicit and explicit instruction. How much so is yet to be determined, but it is exciting to consider the possibilities.

\section{References}

Baghban, M. (1984). Our daughter learns to read and write. Newark, DE: International Reading Association.

Barton, D. (1997). Family literacy programmes and home literacy practices. In D. Taylor (Ed.), Many families, many literacies: An international declaration of principles. (pp. 101-109). Portsmouth, NH: Heinemann.

Berger, E.H. (2000). Parents as partners in education: Families and schools working together $\left(5^{\text {th }}\right.$ ed.). Upper Saddle River, NJ: Merrill/Prentice Hall.

Bissex, G. (1980). Gnys at wrk: A child learns to write and read. Cambridge, MA: Harvard University.

Brody, G., Stoneman, Z., \& MacKinnon, C. (1982). Role asymmetries in interactions among school-aged children, their younger siblings, and their friends. Child Development, 53, 1364-1370.

Cambourne, B. (1995). Toward an educationally relevant theory of literacy learning: Twenty years of inquiry. The Reading Teacher, 49(3), 182-190.

Cook, S. (2005). "Behind closed doors": Discovering the literacies in our children's everyday lives. Language Arts, 82(6), 420-430.

Cook-Gumperz, J. (Ed.). (1986). The social construction of literacy. Cambridge: Cambridge University Press.

Doake, D. (1988). Reading begins at birth. New York: Scholastic.

Epstein, J. (1995). School/family/community partnerships: Caring for the children we serve. Phi Delta Kappan, 76, 701-712.

Ervin-Tripp, S. (1989). Sisters and brothers. In P.G. Zukow (Ed.), Sibling interaction across cultures: Theoretical and methodological issues (pp. 184-195). NewYork: SpringerVerlag.

Gonzalez, N. Moll, L.\& Amanti, C. (2005). Funds of knowledge: Theorizing practices in households, communities, and classrooms. New Jersey: Lawrence Erlbaum Associates.

Gregory, E. (2001). Sisters and brothers as language and literacy teachers: Synergy between siblings playing and working together. Journal of Early Childhood Literacy, 1(3), 301322.

Gregory, E. (2004). 'Invisible' teachers of literacy: collusion between siblings and teachers in creating classroom cultures. Literacy, July, 97-105.

Keats, E. J. (1998). Peter's chair. New York: Puffin.

Lave, J. (1988). The culture of acquisition and the practice of understanding. (IRL report 8800087). Palo Alto, CA: Institute for Research on Learning.

Moll, L. (1994). Presentation at International Forum on Family Literacy, Tucson, Arizona.

Powell, R. \& Davidson, N. (2005). The donut house: Real world literacy in an urban kindergarten classroom. Language Arts, 82(5), 248-256. 
Rogoff, B. (1990). Apprenticeship in thinking: Cognitive development in social context. New York: Oxford University Press.

Schwarzer, D. (2001). Noa's Ark: One child's voyage into multiliteracy. Portsmouth, NH: Heinemann.

Swick, K. (1991). Teacher-parent partnerships to enhance school success in early childhood education. Washington, DC: National Education Association.

Volk, D. (1999). "The teaching and the enjoyment and being together...": Sibling teaching in the family of a Puerto Rican kindergartner. Early Childhood Research Quarterly, 14(1), 534.

Vygotsky, L. (1986). Thought and language. Cambridge, MA: The MIT Press.

Whitmore, K.F., Martens, P., Goodman, Y., \& Owocki, G. (2005). Remembering critical lessons in early literacy research: A transactional perspective. Language Arts, 82(5), 296307.

\section{Author Biographies}

Amy Barnhill teaches in the School of Education and Human Development at the University of Houston-Victoria. She teaches literacy courses at the undergraduate and graduate level and is the field director for student teachers in the Houston area. Her research interests include family literacy as well as technology and literacy development.

Don Halquist, $\mathrm{PhD}$, is an assistant professor in the Department of Education and Human Development at the College at Brockport State University of New York where he teaches courses in literacy, diversity, and qualitative research methods. His current research interests focus on pre-service teacher identity development and the use of critical incidents as means to explore lived experience. 